\title{
Increased reports of Mycoplasma pneumoniae from laboratories in Scotland in 2010 and 2011 - impact of the epidemic in infants
}

N J Gadsby (Naomi.Gadsby@luht.scot.nhs.uk)', A J Reynolds², J McMenamin², R N Gunson³, S McDonagh4, P J Molyneaux, D L Yirrell $^{6}$, K E Templeton ${ }^{1}$

1. Microbiology, Department of Laboratory Medicine, Royal Infirmary of Edinburgh, Edinburgh, Scotland, United Kingdom

2. Health Protection Scotland, Glasgow, Scotland, United Kingdom

3. West of Scotland Specialist Virology Centre, Glasgow, Scotland, United Kingdom

4. Microbiology Department, Raigmore Hospital, Inverness, Scotland, United Kingdom

5. Department of Medical Microbiology, Aberdeen Royal Infirmary, Aberdeen, Scotland, United Kingdom

6. Department of Medical Microbiology, Ninewells Hospital and Medical School, Dundee, Scotland, United Kingdom

Gadsby NJ, Reynolds AJ, McMenamin J, Gunson RN, McDonagh S, Molyneaux PJ, Yirrell DL, Templeton KE. Increased reports of Mycoplasma pneumoniae from laboratories in Scotland in 2010 and 2011 - impact of the epidemic in infants.

Euro Surveill. 2012;17(10):pii=20110. Available online: http://www.eurosurveillance.org/ViewArticle.aspx?Articleld=20110

In common with reports from other European countries, we describe a substantial increase in the number of laboratory reports of Mycoplasma pneumoniae in Scotland in 2010 and 2011. The highest number of reports came from those aged one year and younger. However, reports from young children were more likely to come from PCR testing than serological testing.

In light of the increasing incidence of $M$. pneumoniae in other parts of the United Kingdom (UK) and Europe in 2010 and 2011, we examined the numbers of $M$. pneumoniae laboratory reports in Scotland from January 2008 to December 2011. Here we describe the temporal distribution of reports and the age groups most affected.

\section{Background}

Mycoplasma pneumoniae causes upper and lower respiratory tract infection in all age groups. However, it is a particularly important bacterial cause of communityacquired pneumonia in children [1]. M. pneumoniae is endemic worldwide, but epidemics are common; historically in the UK, these usually occur once every four years [2]. The most recent increase in the incidence of M. pneumoniae was seen in England and Wales in 2010 and $2011[3,4]$. Similar increases have also been noted in many other countries in the same period, particularly in northern Europe [5-12].

Although the main burden of infection is typically found in school-age children $[4,6,10]$, M. pneumoniae has also been noted as a significant cause of respiratory tract infection in children under the age of five [13-15]. As the possibility of $M$. pneumoniae infection may be overlooked in young children, recent UK clinical guidelines emphasise that $M$. pneumoniae is not uncommon in those aged one to five years [1]. However, the local availability of different testing methodologies for M. pneumoniae may determine how frequently M. pneumoniae is diagnosed in particular age groups.

National laboratory-based surveillance and reporting

In Scotland, some diagnostic laboratories carry out PCR testing for $M$. pneumoniae as part of a multiplex realtime PCR screening approach for respiratory viruses [16]. Therefore, young children presenting with presumed respiratory viral infection to hospitals served by these laboratories also receive concomitant testing for M. pneumoniae. In hospitals served by other laboratories, serology is still the mainstay of $M$. pneumoniae diagnosis. However, serology is less convenient for diagnosis in young children, since obtaining a blood specimen from an infant is more difficult than obtaining an upper respiratory tract specimen.

Reports of M. pneumoniae from National Health Service (NHS) laboratories in Scotland are collated centrally by the national public health body Health Protection Scotland (HPS), via the Electronic Communication Of Surveillance in Scotland (ECOSS) non-mandatory reporting system. Reports from 1 January 2008 to 31 December 2011 inclusive were analysed in this study. Denominator testing data and clinical diagnosis were not recorded via ECOSS. Data were anonymised and analysed by week of year reported, age group (year of age was available in 2010 and 2011), sex, submitting laboratory and specimen type. Estimates of incidence were based on the most recent mid-year population estimate for Scotland [17]. Reports were submitted from all NHS microbiology laboratories in Scotland which carry out $M$. pneumoniae testing. These are based in hospitals in nine locations: Aberdeen, Ayr, Dundee, Dunfermline, Edinburgh, Fife, Glasgow, Inverness and 
Lanarkshire. In the case of Glasgow, results from two laboratories in the city were combined. Respiratory specimens were tested by PCR and blood specimens by serology. Laboratories used a number of different commercial and in-house PCR and serological tests. Reports of positive serology were either from a diagnostic rise in $M$. pneumoniae-specific IgG antibodies or detection of $M$. pneumoniae-specific IgM.

\section{Analysis of laboratory reports \\ Temporal distribution}

During the study period, there were 1,232 laboratory reports of $M$. pneumoniae in Scotland; of these, 76 (6.2\%) were from 2008, 125 (10.1\%) from 2009, 290 (23.5\%) from 2010 and 741 (60.1\%) from 2011. The highest number of reports were found in the fourth quarter of 2011 (432 reports); this was nearly three times higher than in any other quarter in the study period. The number of reports began to rise from the autumn of 2010 through the winter of $2010 / 11$, with a second and larger rise towards the end of 2011 (Figure 1). The peak reporting frequency was 48 reports in week 47 of 2011. The estimated national incidence of $M$. pneumoniae in 2011 was 14.2 per 100,000 population.

\section{Laboratory testing}

Reports of $M$. pneumoniae were issued from nine laboratories, with the two laboratories serving the largest populations (Edinburgh and Glasgow) issuing $77.0 \%$ of the reports. Testing methods differed across Scotland, with five laboratories using PCR only and four using serology only. Overall, $77.4 \%$ of reports were from respiratory specimens (PCR detection), $18.0 \%$ from serology, and the specimen type was not known in $4.6 \%$ of reports. Of the respiratory specimens, $92.1 \%$ were from the upper respiratory tract.

\section{Patient demographics}

The male:female ratio was 1:0.94; there was no significant difference in the number of reports from males and females ( $p=0.30$; chi-squared test). Approximately half of the reports (53\%) were from children under the age of 15 years, with the age group of $0-4$ yearolds accounting for $24.9 \%$ of all reports (Table). The

\section{FIGURE 1}

Mycoplasma pneumoniae reports by week of year, Scotland 2008-2011 $(\mathrm{n}=1,232)$

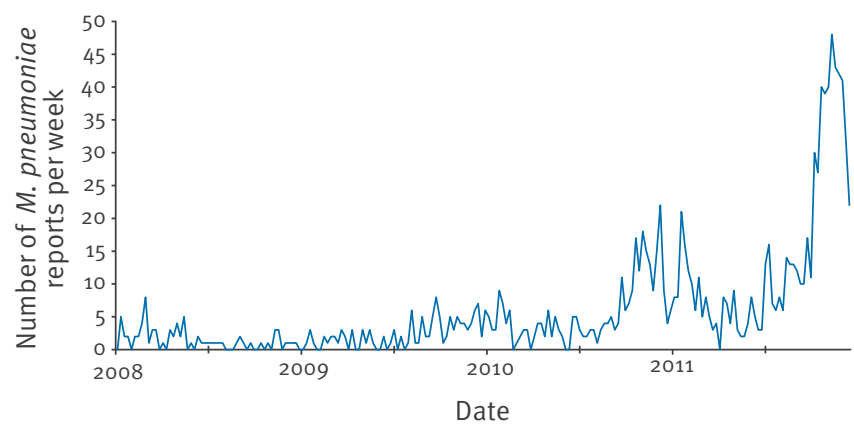

estimated incidence of $M$. pneumoniae in 2011 was highest in the $0-4$ year-olds (67.5/100,000 population), declining to 52.2 per 100,000 in the 5-9 year-olds and 22.6 per 100,000 in the 10-14 year-olds.

Due to improvements in the quality of information provided from laboratories via ECOSS, data on individual year of age were available from 2010 onwards. The mean age of patients was 20.0 years (standard deviation (SD) +/-19.8 years; range: 11 month to 89 years), however, $16.2 \%$ of the reports from 2010 and 2011 came from patients aged one year or younger (Figure 2).

\section{Patient age and sample type}

Between 2008 and 2011, M. pneumoniae reports from young children were more likely to come from PCR testing than serological testing: $28.8 \%$ of reports from respiratory specimens were from 0-4 year-old children, compared to $10.4 \%$ of serology specimens ( $p<0.01$ Fisher's exact test) (Table).

An analysis of year of age data from 2010/11 demonstrated that the mean age for PCR reports was 18.6 years (SD +/-19.4 years; range: $<1$ month to 89 years). In contrast, the mean age for serology reports during the same period was 27.8 years $(S D+/-19.9$ years; range: 1 year to 88 years).

\section{Macrolide resistance}

A full analysis of the presence of mutations in the 23S rRNA gene associated with macrolide resistance is currently underway in PCR-positive specimens.

\section{TABLE}

Mycoplasma pneumoniae reports by age group and specimen type, Scotland, 2008-2011 $(\mathrm{n}=1,232)$

\begin{tabular}{|c|c|c|c|}
\hline $\begin{array}{l}\text { Age group } \\
\text { (years) }\end{array}$ & $\begin{array}{l}\text { Total } \\
\text { M. pneumoniae } \\
\text { reports (\%) } \\
n=1,232\end{array}$ & $\begin{array}{l}\text { M. pneumoniae } \\
\text { reports from } \\
\text { respiratory } \\
\text { specimens (\%) } \\
n=954^{\mathrm{a}}\end{array}$ & $\begin{array}{c}\text { M. pneumoniae } \\
\text { reports from } \\
\text { serology (\%) } \\
n=222^{\mathrm{a}}\end{array}$ \\
\hline $0-4$ & 307 (24.9) & 275 (28.8) & $23(10.4)$ \\
\hline $5-9$ & $218(17.7)$ & $173(18.1)$ & $40(18.0)$ \\
\hline $10-14$ & $128(10.4)$ & $97(10.2)$ & $28(12.6)$ \\
\hline $15-19$ & $67(5.4)$ & $45(4 \cdot 7)$ & $14(6.3)$ \\
\hline $20-24$ & $60(4.9)$ & $41(4 \cdot 3)$ & $15(6.8)$ \\
\hline $25-29$ & $55(4.5)$ & $45(4 \cdot 7)$ & $6(2.7)$ \\
\hline $30-34$ & 75 (6.1) & $55(5.8)$ & $20(9.0)$ \\
\hline $35-39$ & $75(6.1)$ & $59(6.2)$ & $12(5.4)$ \\
\hline $40-44$ & $73(5.9)$ & $45(4 \cdot 7)$ & 22 (9.9) \\
\hline $45-49$ & $43(3.5)$ & $31(3.2)$ & $8(3.6)$ \\
\hline $50-54$ & $39(3.2)$ & $24(2.5)$ & $11(5.0)$ \\
\hline $55-59$ & $26(2.1)$ & $19(2.0)$ & $6(2.7)$ \\
\hline $60-64$ & $17(1.4)$ & $12(1.3)$ & $4(1.8)$ \\
\hline$\geq 65$ & $49(4.0)$ & $33(3.5)$ & $13(5 \cdot 9)$ \\
\hline
\end{tabular}

a 56 reports were from specimens of unknown type and are therefore excluded here. 
However, preliminary results indicate genotypic evidence of resistance in at least one specimen; a paediatric patient re-presenting to hospital with ongoing respiratory symptoms following first-line treatment with a macrolide for $M$. pneumoniae infection (data not shown).

\section{Discussion}

An examination of the current epidemiology of M. pneumoniae in Scotland was considered timely given the recent increasing incidence seen in other countries in the UK, Europe and elsewhere [3-12]. We found a substantial peak in the number of $M$. pneumoniae laboratory reports submitted to the national surveillance programme during the autumn/winter of 2011, following a smaller peak in the previous autumn/ winter of 2010. The M. pneumoniae activity had been low from 2008 until the autumn of 2010. As expected, this picture is consistent with an increase in M. pneumoniae laboratory reports in England and Wales in the same period $[3,4]$. The estimated overall incidence of M. pneumoniae in Scotland in 2011 was around 10 -fold lower than that reported in other northern European countries $[8,10]$. However, we found that the incidence was highest in the youngest age group, in contrast to a recent study in which incidence was highest in 5-14 year-olds [10]. Reporting of $M$. pneumoniae in the UK is not mandatory and reports only arise from the active microbiological investigation of patients with respiratory symptoms, mainly those presenting to hospitals. Therefore, our figures are likely to underestimate the true extent of the epidemic in Scotland, particularly in the community.
Low levels of macrolide resistance have been reported in Europe $[11,18]$ but not from other countries in the UK $[3,4]$. In a preliminary analysis as part of the present study we found one genotypically resistant isolate, however, a full assessment of the level of macrolide resistance in Scotland is required and is now underway.

As we were able to differentiate reports into narrow age bands, it was clear that in Scotland, M. pneumoniae was most frequently reported in the youngest children, particularly those one year and younger. The incidence was also highest in the age group of $0-4$ year-olds, with 67.5 per 100,000 . A limitation of this study is that denominator testing data is not currently captured by the surveillance programme, so we are unable to determine if the proportion of $M$. pneumoniae-positive children in this age group was less than that in older age groups, as found in other studies $[4,6,10]$. Numerically however, we have found a significant burden in infants, which has previously been under-appreciated. A study examining the clinical course, treatment and outcomes of $M$. pneumoniae infection in infants is now underway.

We also found significantly fewer $M$. pneumoniae reports from serology compared to respiratory specimens in children aged 0-4 years. This may be due to the ease of obtaining upper respiratory tract specimens for PCR, compared to blood specimens for serology, in the youngest patients. Therefore, in hospitals where only serological testing is available, M. pneumoniae infections in young children may be under-diagnosed.

The majority of $M$. pneumoniae reports in Scotland originated from two large laboratories which test almost exclusively by PCR as part of in-house multiplex

\section{FIGURE 2}

Mycoplasma pneumoniae reports by year of age, Scotland, 2010-2011 (n=1,031)

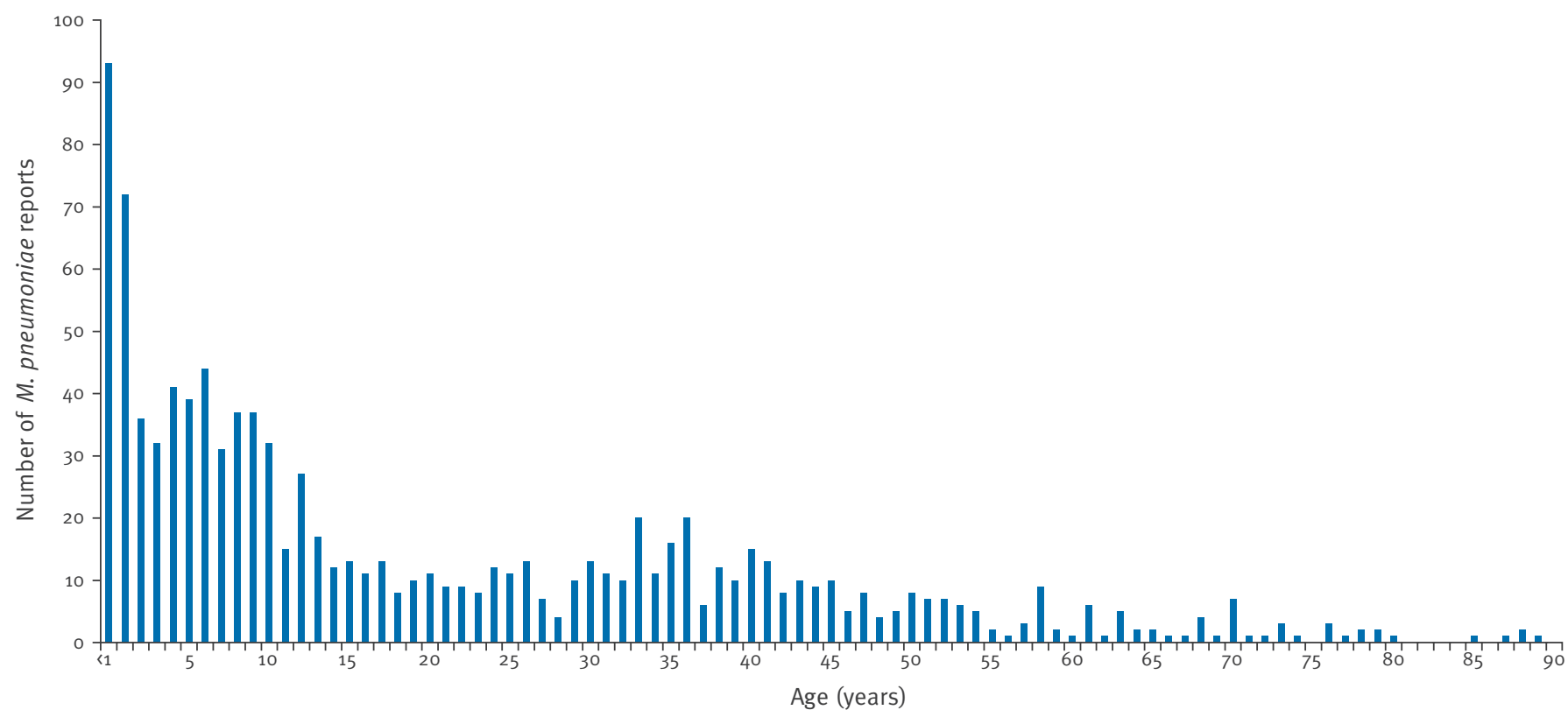


real-time PCR screens for respiratory pathogens. In the future, as this molecular syndromic screening approach becomes more widespread, more infants are likely to be tested for M. pneumoniae, and more infections found. During $M$. pneumoniae epidemics, there may be a requirement to change empirical prescribing for community-acquired pneumonia from beta-lactam antibiotics to macrolides in the most affected age groups. However, further work is required to determine the clinical consequences of $M$. pneumoniae infection in infants and the need for antibiotic treatment.

\section{Acknowledgments}

The authors would like to thank the staff of the NHS Scotland virology and microbiology laboratories who kindly submitted reports, and Dr Beatrix von Wissman at Health Protection Scotland.

\section{Funding}

This work was supported by NHS Education for Scotland (NES) through the Clinical Scientist Training Programme.

\section{References}

1. Harris M, Clark J, Coote N, Fletcher P, Harnden A, McKean M, et al. British Thoracic Society guidelines for the management of community acquired pneumonia in children: update 2011. Thorax. 2011;66(Suppl 2):ii1-23.

2. Chalker VJ, Stocki T, Mentasti M, Fleming D, Sadler C, Ellis J, et al. Mycoplasma pneumoniae infection in primary care investigated by real-time PCR in England and Wales. Eur J Clin Microbiol Infect Dis. 2011;30(7):915-21.

3. Chalker VJ, Stocki T, Mentasti M, Fleming D, Harrison TG. Increased incidence of Mycoplasma pneumoniae infection in England and Wales in 2010: multiocus variable number tandem repeat analysis typing and macrolide susceptibility. Euro Surveill. 2011;16(19):pii=19865. Available from: http://www. eurosurveillance.org/ViewArticle.aspx?Articleld $=19865$

4. Chalker VJ, Stocki T, Litt D, Bermingham A, Watson J, Fleming $D$, et al. Increased detection of Mycoplasma pneumoniae infection in children in England and Wales, October 2011 to January 2012. Euro Surveill. 2012;17(6):pii=20081. Available from: http://www.eurosurveillance.org/ViewArticle. aspx?Articleld $=20081$

5. Blystad H, Ånestad G, Vestrheim D, Madsen S, Rønning K. Increased incidence of Mycoplasma pneumoniae infection in Norway 2011. Euro Surveill. 2012;17(5):pii=20074. Available from: http://www.eurosurveillance.org/ViewArticle. aspx?Articleld $=20074$

6. Eibach D, Casalegno JS, Escuret V, Billaud G, Mekki Y, Frobert $E$, et al. Increased detection of Mycoplasma pneumoniae infection in children, Lyon, France, 2010 to 2011. Euro Surveill. 2012;17(8):pii=20094. Available from: http://www. eurosurveillance.org/ViewArticle.aspx?Articleld=20094

7. Lenglet A, Herrador Z, Magiorakos A, Leitmeyer K, Coulombier D, European Working Group on Mycoplasma pneumoniae surveillance. Surveillance status and recent data for Mycoplasma pneumoniae infections in the European Union and European Economic Area, January 2012. Euro Surveill. 2012;7(5):pii=20075. Available from: http://www. eurosurveillance.org/ViewArticle.aspx?Articleld $=20075$

8. Linde A, Ternhag A, Törner A, Claesson B. Antibiotic prescriptions and laboratory-confirmed cases of Mycoplasma pneumoniae during the epidemic in Sweden in 2011. Euro Surveill. 2012;17(6):pii=20082. Available from: http://www. eurosurveillance.org/ViewArticle.aspx?Articleld $=20082$

9. Nir-Paz R, Abutbul A, Moses AE, Block C, HidalgoGrass C. Ongoing epidemic of Mycoplasma pneumoniae infection in Jerusalem, Israel, 2010 to 2012. Euro Surveill. 2012;17(8): pii=20095. Available from: http://www. eurosurveillance.org/ViewArticle.aspx?Articleld=20095

10. Polkowska A, Harjunpää A, Toikkanen S, Lappalainen $M$, Vuento R, Vuorinen T, et al. Increased incidence of Mycoplasma pneumoniae infection in Finland, 2010-2011. Euro
Surveill. 2012;17(5):pii=20072. Available from: http://www. eurosurveillance.org/ViewArticle.aspx?Articleld $=20072$

11. Uldum SA, Bangsborg JM, Gahrn-Hansen B, Ljung R, Mølvadgaard M, Føns Petersen R, et al. Epidemic of Mycoplasma pneumoniae infection in Denmark, 2010 and 2011. Euro Surveill. 2012;17(5):pii=20073. Available from: http:// www.eurosurveillance.org/ViewArticle.aspx?Articleld=20073

12. Japanese Infectious Disease Surveillance Center. Mycoplasma Pneumonia reported per sentinel weekly. Infectious Disease Weekly Report. Tokyo: Infectious Disease Surveillance Center. [Accessed 8 March 2012]. Available from: http://idsc.nih. go.jp/idwr/kanja/weeklygraph/18myco-e.html

13. Weigl JA, Puppe W, Gröndahl B, Schmitt HJ. Epidemiological investigation of nine respiratory pathogens in hospitalized children in Germany using multiplex reverse-transcriptase polymerase chain reaction. Eur J Clin Microbiol Infect Dis. 2000;19(5):336-43.

14. Principi N, Esposito S, Blasi F, Allegra L, The Mowgli Study Group. Role of Mycoplasma pneumoniae and Chlamydia pneumoniae in children with community-acquired lower respiratory tract infections. Clin Infect Dis. 2001;32: 1281-9.

15. Defilippi A, Silvestri M, Tacchella A, Giacchino R, Melioli G, Di Marco E, et al. Epidemiology and clinical features of Mycoplasma pneumoniae infection in children. Respir Med. 2008;102(12):1762-8.

16. Gunson RN, Bennett S, Maclean A, Carman WF. Using multiplex real time PCR in order to streamline a routine diagnostic service. J Clin Virol. 2008;43(4):372-5.

17. General Register for Scotland. Mid-2010 population estimates Scotland. Edinburgh: National Records of Scotland (NRS); 27 April 2011. Available from: http://www.gro-scotland.gov.uk/ statistics/theme/population/estimates/mid-year/2010/index. html

18. Dumke R, von Baum H, Lück PC, Jacobs E. Occurrence of macrolide-resistant Mycoplasma pneumoniae strains in Germany. Clin Microbiol Infect. 2010;16(6):613-6. 